and in many parts of the world were wondering how to improve their lot in the face of Europe's global imperialism. So from Egypt to India, China and Japan, many religious scholars embraced Darwin's ideas, often showing how their own schools of thought had anticipated the notion of evolution. Against the threat of Western imperialism and Western charges of 'backwardness', it was to their advantage to highlight the rationality of their creed.

In China, Darwin's ideas were seen as supporting Confucians' belief in the perfectibility of the cosmic order. Evolutionary theory also became fodder for political movements of revolution and reform, and eventually laid the groundwork for communism. Latin American politicians initially reacted to Darwin's ideas by attempting to entice white Europeans to emigrate and intermarry with local populations, believing that this would 'improve the stock'. But after two world wars had made European culture look less impressive, Latin America began to see its racial diversity as an advantage, and moved towards a social view that favoured a homogeneous blend of cultures.

In nineteenth-century Russia, meanwhile, a tendency to distrust rabid, dog-eat-dog capitalism helped incline naturalists away from a view of evolution that emphasized competition between species. Instead they embraced a 'theory of mutual aid', an account that focused on the role of cooperation in ensuring survival in a harsh environment.

The lesson for today's scientists and policy-makers is simple: they cannot assume that a public presented with 'the facts' will come to the same conclusion as themselves. They must take value systems, cultural backdrops and local knowledge gaps into account and frame their arguments accordingly. Such approaches will be crucial in facing current global challenges, from recessions to pandemics and climate change. These issues will be perceived and dealt with differently by different nations - not because they misunderstand, but because their understanding is in part locally dependent.

Darwin once said: "But then with me the horrid doubt always arises whether the convictions of man's mind, which has been developed from the mind of the lower animals, are of any value or at all trustworthy." Researchers and policy-makers would do well to mimic his humility when presenting science, and remember how people's minds truly work.

\section{Mind the spin}

\section{Scientists - and their institutions - should resist the ever-present temptation to hype their results.}

T

he circumstances surrounding the recent announcement of results from an HIV vaccine trial in Thailand are troubling.

The sponsors of the US\$119-million phase III clinical trial, a consortium led by the US Army, the National Institutes of Health and the Thai government, announced on 24 September that the trial had been a success: an analysis of the data showed that the vaccine had a statistically significant effect on preventing infection.

Other scientists could not immediately assess that claim, however: the full data from the trial were not made available until 20 October, when they were presented at an AIDS vaccine conference in Paris and in an article published online the same day (S. Rerks-Ngarm et al. N. Engl. J. Med. doi:10.1056/nejmoa0908492; 2009). The article contained two other data analyses, not mentioned in the initial announcement, showing smaller effects that were not statistically significant (see page 1187).

The trial's sponsors defend the premature announcement on the grounds that they had promised to inform the Thai people of the results first; 24 September is also Mahidol Day, the anniversary of the death of the king's father and a day of national observance in Thailand. The sponsors also argue that announcing the less-upbeat analyses along with the positive result would have been too complicated for the public to understand; they wanted to quickly deliver a clear-cut message on the trial's findings. Making the full data immediately available to scientists on 24 September would also have been impossible, they add, because of the conference and journal embargoes.

To their credit, the scientists involved did emphasize in their public statements that any vaccine effect was "modest", and that the vaccine itself was of no immediate public-health utility. At the same time, however, they hammered home the message that this was "the first time an HIV vaccine has successfully prevented HIV infection in humans", and implied that the event was somehow historic. Such statements, together with the selective initial presentation of the data, are well outside the scientific norms for presenting the results of clinical trials. They inevitably create suspicion that the trial sponsors may have put an excessively positive spin on results that are far from clear-cut, in a trial that has long been controversial (T. V. Padma Nature Med. 10, 1267; 2004). The trial has also been six years in the works, and so there seems no particular public-health urgency to justify publication by press conference.

Fortunately, such stories are still rare in science. Witness the way scientists have behaved since the begin-
"The trial sponsors argue that announcing the less-upbeat analyses along with the positive result would have been too complicated for the public to understand." ning of the current H1N1 flu pandemic, in which the urgent threat to health creates legitimate tensions between getting results out fast and respecting peer review. Most researchers have negotiated this tension well, through a combination of fast-track publication by journals and online pre-publication sharing of preliminary data but not through hyping their results.

Yet the temptation for scientists and their institutions to spin their research to the media, or to go publicity-mongering, is always there. And - as illustrated by the excessive public-relations campaign surrounding Ida, a fossil presented as a missing link in human evolution (see Nature 459, 484; 2009 and 461, 1040; 2009) - too many in the media will buy into the initial hype.

Such behaviour is corrosive to the process of scholarly scientific communication. Research institutions must not allow it to become the norm. 